\title{
Time use by trainees in medical education
}

DOUGLAS L. WOOD, DO, PHD

MARTIN J. HOGAN, PHD

\begin{abstract}
Fifteen trainess $(7$ students, 7 interns, 1 resident) in a 288 -bed community teaching hospital recorded their activities and the time spent on them over a sevenday period. The participants also reported the major diagnosis of the patients with whom they interacted, the location of each activity, and whether the activity was observed or performed. Data analysis demonstrated a significant relationship between the types of activities or procedures reported and the level of training. Likewise, significantrelationships were found between the level of training and whether an activity was observed or performed, and between the training level and the types of cases seen.
\end{abstract}

Trainees in medical education programs complain about not having enough time to complete assigned tasks or to carry out extra reading or investigation. One aspect of time that is handled in a different way by each person is allocation of this resource. This factor seems to be particularly evident when one focuses on the use of time in educational endeavors.

The use of time, whether effective or ineffective, has definite educational implications. Therefore, to determine how time was utilized by trainees in a medical education setting, a study was devised to collect time-activity data for analysis, and educational implications were drawn from the study findings.

\section{Procedures and methods}

Study participants consisted of 15 trainees who were in rotation on an internal medicine service at a 288-bed community teaching hospital. Seven senior medical students, seven interns, and one resident were included in the study.

Participants were asked to record their activities during each working day over a seven-day study period. Entries were made on a log sheet (Fig. 1 ), with activities recorded every 15 minutes. Examples of activities or procedures to be reported were provided to the participants (Fig. 2). The lo- cation wherein each activity took place was recorded also. If patient contact was involved, the primary diagnosis was entered. Others present during the performance of the activity or procedure also were listed. Finally, the trainees were asked to indicate whether they observed or performed the procedure.

The activity and procedure entries, location, others present during activity, and the procedure status data were coded and entered onto a standard computer tape. Time data were analyzed by a simple time ending minus time beginning technique. The patient's major diagnosis was coded using the Hospital Adaptation of the International Classification of Diseases (HICDA) system. Data analyses were performed with a standard statistical computer package.

The unit of measurement was 15-minute time intervals for approximately 17 hours per each day of the study. By definition, an observation point consisted of that time interval during which a single activity took place. The amount of time that had elapsed during this activity or procedure was recorded, and the unit of analysis then became that time period.

\section{Results}

The average number of hours on duty for each of these groups (externs, interns, residents) studied during the seven days is presented in Table 1 . The average medical student was on duty 101.1. hours (16.9 hours per day), during six of the seven days in the study period. Interns worked an average of 113.3 hours ( 18.9 hours per day), with interns working six days of the study period. The single resident in the study reported being on duty five days; he averaged 15.8 hours per day and reported 78.8 hours for the total observational period.

Seventeen different activities or procedures were recorded. Table 2 lists the frequency for each of these 17 items. Table 3 depicts the total time spent on the reported activities by the entire group of trainees. A further break down of these data into time spent by an average member of each group is presented in Table 4.

If trainees are not exposed to an adequate case 
INTERNAL MEDICINE STUDY

\begin{tabular}{|l|}
\hline DATE: \\
\hline MAME: \\
\hline
\end{tabular}

\begin{tabular}{|c|c|c|c|c|c|c|c|}
\hline \multicolumn{2}{|c|}{ TIME (1) } & \multirow{2}{*}{ ACTIVITY OT PROCEDURE (2) } & $\begin{array}{c}\text { LOCATION } \\
\text { (3) }\end{array}$ & $\begin{array}{c}\text { PATIENT'S } \\
\text { MAJOR DIAGNOSIS (4) }\end{array}$ & $\begin{array}{c}\text { OTHERS PAESENT } \\
\text { DURING ACTIVITY (5) }\end{array}$ & $\begin{array}{l}\text { PAOCEDURE } \\
\text { STATUS (8) }\end{array}$ \\
\hline & & & & & & & \\
\hline & & & & & & & \\
\hline & & & & & & & \\
\hline & & & & & & & \\
\hline & & & & & & & \\
\hline & & & & & & & \\
\hline & & & & & & & \\
\hline & & & & & & \\
\hline & & & & & & & \\
\hline & & & & & & & \\
\hline & & & & & & & \\
\hline & & & & & & & \\
\hline & & & & & & & \\
\hline & & & & & & & \\
\hline & & & & & & & \\
\hline
\end{tabular}

\section{INSTRUCTIONS:}

1) Enter time starting and ending activity to the nearest $1 / 4$ hour - use military time.

2) Enter activities or procedures in which you participated or observed. Examples of some are on the attached sheet. Account for all activities in the assigned seven day period except for personal activities.

3) Enter the location of the activity or procedure, (i.e. - E.R., I.C.U., patient floor)

4) Enter the major diagnosis of each patient with whom you interacted.

5) List others present during the activity or procedure, (i.e. - staff physician, intern, resident)

6 ) If a procedure has been performed list whether you performed $(P)$, or observed $(O)$

Fig 1. Participants' log sheet.

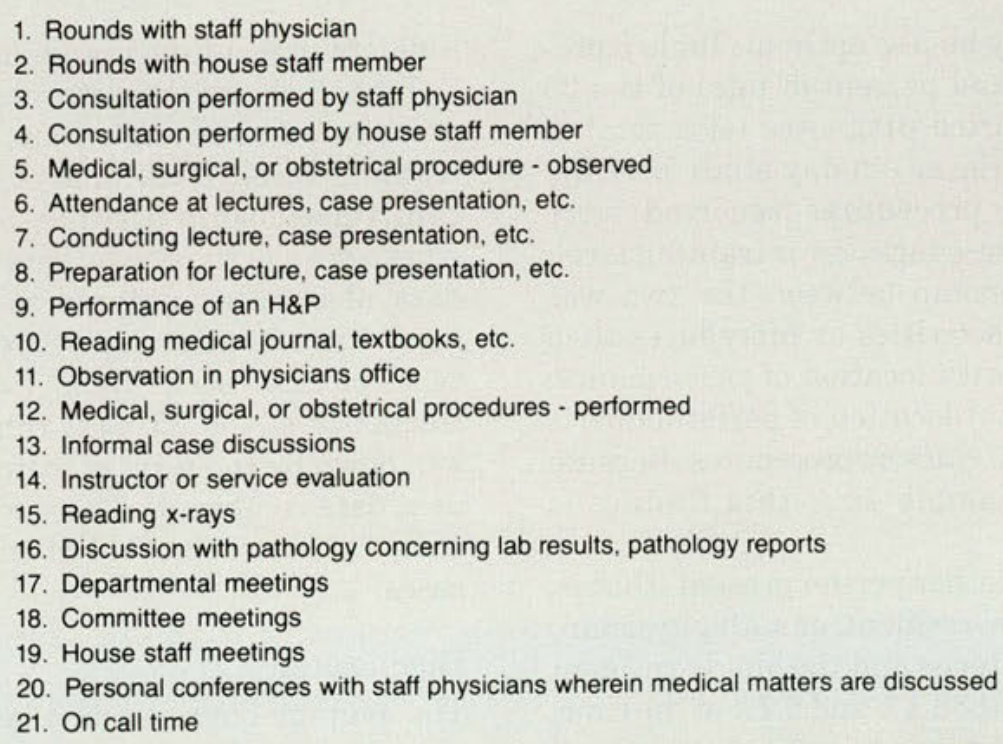

Fig 2. Examples of activities and procedures to be recorded by participants. 


\begin{tabular}{|c|c|c|c|c|}
\hline $\begin{array}{l}\text { Educational } \\
\text { level }\end{array}$ & Number & Total hours & $\begin{array}{c}\text { Average } \\
\text { total hours }\end{array}$ & $\begin{array}{c}\text { Average hours } \\
\text { per day* }\end{array}$ \\
\hline $\begin{array}{l}\text { Extern } \\
\text { Intern } \\
\text { Resident }\end{array}$ & $\begin{array}{l}7 \\
7 \\
1 \\
\end{array}$ & $\begin{array}{r}707.7 \\
793.1 \\
78.8 \dagger \\
\end{array}$ & $\begin{array}{r}101.1 \\
113.3 \\
78.8 \\
\end{array}$ & $\begin{array}{l}16.9 \\
18.9 \\
15.8 \\
\end{array}$ \\
\hline Total & 15 & $1,579.6 \dagger$ & 293.2 & 17.3 \\
\hline
\end{tabular}

\begin{tabular}{|lcc|}
\hline \multicolumn{2}{|c|}{ TABLE 2. TOTAL ACTIVITIES OR PROCEDURES RECORDED. } \\
\hline Activity & Frequency & $\begin{array}{r}\text { Percent } \\
\text { of total }\end{array}$ \\
\hline Rounds & 857 & 27.0 \\
Patient evaluation & 509 & 16.1 \\
Personal & 501 & 15.8 \\
Performance history taking & 372 & 11.7 \\
and physical examination & 246 & 7.8 \\
Reading & 194 & 6.1 \\
Procedure observation & 160 & 5.1 \\
Observing or performing & 99 & 3.1 \\
consultation & 71 & 2.2 \\
On call & 62 & 2.0 \\
Case discussion & 45 & 1.4 \\
Attending lecture & & \\
Reading x-rays & 17 & 0.5 \\
Drawing arterial & 10 & 0.3 \\
blood gas samples & & \\
Miscellaneous procedures & 9 & 0.3 \\
Inserting central venous & 6 & 0.2 \\
pressure catheter & 6 & 0.2 \\
Drawing venous blood & 5 & 0.2 \\
Reading ECGs & 3,169 & 100.0 \\
Observing bronchoscopy & & \\
Total & &
\end{tabular}

mix, the training may be less optimal. Table 5 presents the frequency and percent of total of the 25 most frequently reported diagnoses (of a total of 212 reported during the seven-day study period).

The activities or procedures reported were crosstabulated with the education or training level. A significant relationship between the two was found. The recorded activities or procedures then were crosstabulated with location of performance. Analysis indicated that location of performance is not independent of activities or procedures. Because of the insufficient sample size, this finding is merely suggestive.

Interns reported another person present (that is, extern, another intern, resident, or staff physician) $56.2 \%$ of the time. Externs and the single resident reported others present $38.1 \%$ and $5.7 \%$ of the time, respectively. Analysis tends to indicate that level of training is not independent of whether other per-

\begin{tabular}{|lcc|}
\hline \multicolumn{3}{|l|}{ TABLE 3. TOTAL TIME SPENT ON REPORTED ACTIVITES FOR ALL } \\
GROUPS. & Total hours & $\begin{array}{r}\text { Percent } \\
\text { of total }\end{array}$ \\
\hline Activity & 362.7 & 22.8 \\
\hline Rounds & 281.7 & 17.7 \\
Personal & 233.2 & 14.6 \\
Patient evaluation & 232.2 & 14.6 \\
Performance history taking & 164.0 & 10.3 \\
$\quad$ and physical examination & 78.9 & 5.0 \\
Reading & & \\
Procedure observation & 78.4 & 5.0 \\
Observing or performing & 54.6 & 3.4 \\
consultation & 32.3 & 2.0 \\
On call & 31.2 & 2.0 \\
Case discussion & 17.8 & 1.1 \\
Attending lecture & & \\
Reading x-rays & 7.7 & 0.5 \\
Drawing arterial & & \\
blood gas samples & 6.1 & 0.3 \\
Inserting central venous & 3.8 & 0.2 \\
pressure catheter & 3.8 & 0.2 \\
Observing bronchoscopy & 3.3 & 0.2 \\
Miscellaneous procedures & 1.8 & 0.1 \\
Reading ECGs & $1,593.5$ & 100.0 \\
Drawing venous blood & & \\
Total & & \\
\cline { 2 - 3 } & &
\end{tabular}

sons are present during an activity or procedure.

Table 6 shows the percentages of activities and procedures observed versus those performed by training level. Data analysis indicates a significant relationship between level of training and whether an activity is observed or performed. The data also were analyzed to determine whether there was a relationship between training level and types of cases seen. Table 7 depicts the reporting frequency of the 25 most common diagnoses broken down by the level of training (intern and resident data combined). There was a significant relationship between level of training and kinds of cases.

\section{Discussion}

The average hours on duty reported by each level of trainee was slightly greater than had been expected. Personal time occupied $17.7 \%$ of the total 


\section{non-insulin-dependent}

\section{Diabetes and drug excretion}

The metabolites of MicroNASE are excreted 50\% via the liver and $50 \%$ via the kidneys, which is qualitatively different from other sulfonylureas that are excreted primarily in the urine.

This unique dual excretion may reduce the risk of drug accumulation and hypoglycemia.

Caution should be exercised in patients with reduced renal function. In a single-dose study of patients with varying degrees of renal impairment, plasma clearance was prolonged in only the one patient with severe renal impairment. ${ }^{1}$

All sulfonylureas, including MicronASE, can cause severe hypoglycemia. Proper patient selection, dosage, and instructions are important.

\section{No other oral antidiabetic agent fits the realities of life better than}

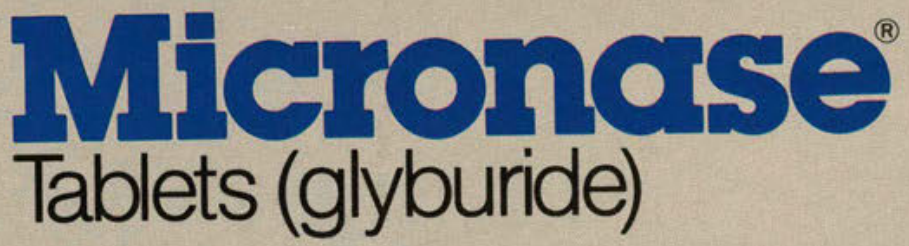

Usual starting dosage- $2.5 \mathrm{mg}$ to $5 \mathrm{mg}$ once a day

When diet alone fails...MICRONASE

Please see adjacent page for brief summary of prescribing information.

'Pearson JG, Antal EJ, Albert KS, Welling PG: Pharmacokinetic disposition of

${ }^{14} \mathrm{C}$-glyburide in patients with varying renal function. Diabetes 1984;33 (suppl):104A. 

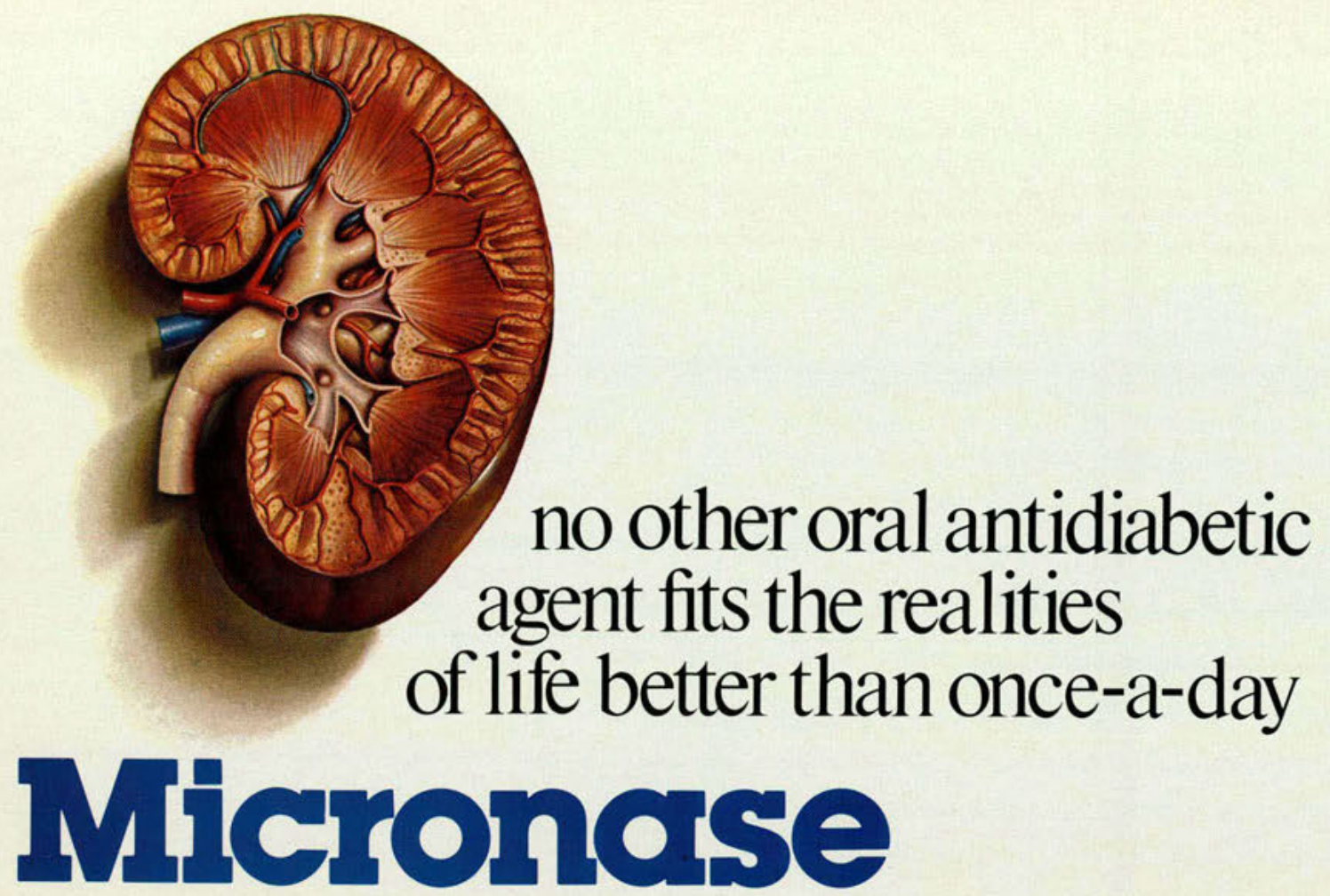

Some patients, particularly those receiving more than $10 \mathrm{mg}$ daily, may have a more satisfactory response with twice-a-day dosage.

Micronase Tablets (glyburide)

CONTRAINDICATIONS: MICRONASE Tablets are contraindicated in patients with: 1. Known hypersensitivity or allergy to the drug. 2. Diabetic ketoacidosis, with or without coma. This condition should be treated with insulin. 3. Type I diabetes mellitus, as sole therapy.

SPECIAL WARNING ON INCREASED RISK OF CARDIOVASCULAR MORTALITY: The administration of oral hypoglycemic drugs has been reported to be associated with increased cardiovascular mortality as compared to treatment with diet alone or diet plus insulin. This warning is based on the study conducted by compared to treatment with diet alone or diet plus insulin. This warning is based on the study conducted by
the University Group Diabetes Program (UGDP), a long-term prospective clinical trial designed to evaluate the effectiveness of glucose-lowering drugs in preventing or delaying vascular complications in patients with noninsulin-dependent diabetes. The study involved 823 patients who were randomly assigned to on of four treatment groups (Diabetes, 19 [Suppl 2):747-830, 1970).

UGDP reported that patients treated for 5 to 8 years with diet plus a fixed dose of tolbutamide ( $1.5 \mathrm{grams}$ per day) had a rate of cardiovascular mortality approximately $2 \% / 2$ times that of patients treated with diet alone. A significant increase in total mortality was not observed, but the use of tolbutamide was discontinued based on the increase in cardiovascular mortality, thus limiting the opportunity for the study to show an increase in overall mortality. Despite controversy regarding the interpretation of these results, the findings of the UGDP study provide an adequate basis for this warning. The patient should be informed of the potential risks and advantages of MICRONASE and of alternative modes of therapy.

Although only one drug in the sulfonylurea class (tolbutamide) was included in this study, it is prudent from a safety standpoint to consider that this warning may apply to other oral hypoglycemic drugs in this class. in view of their close similarities in mode of action and chemical structure.

PRECAUTIONS: General-Hypoglycemia: All sulfonylureas are capable of producing severe hypoglycemia. Proper patient selection and dosage and instructions are important to avoid hypoglycemic episodes. Renal or hepatic insufficiency may increase the risk of serious hypoglycemic reactions. Elderly, debilitated or malnourished patients, and those with adrenal or pituitary insufficiency, are particularly susceptible to the hypoglycemic action of glucose-lowering drugs. Hypoglycemia may be difficult to recognize in the elderly and in people who are taking beta-adrenergic blocking drugs. Hypoglycemia is more likely to occur when caloric intake is deficient, after severe or prolonged exercise, when alcohol is ingested, or when more than one glucose lowering drug is used. Loss of Control of Blood Glucose. In diabetic patients exposed to stress such as fever, trauma, infection or surgery, a loss of control may occur. It may then be necessary to discontinue MICRONASE and administer insulin. Adequate adjustment of dose and adherence to diet should be assessed before classifying a patient as a secondary failure. Information for Patients: Patients should be informed of the potential risks and advantages of MICRONASE and of alternative modes of therapy. They a should be informed about the importance of adherence to dietary intructions, of a regular exerciseprals and of regular testing of urine and/or blood glucose. The risks of hypoglycemia, its symptoms and treatment, and conditions that predispose to its development should be explained to patients and responsible family members. Primary and secondary failure should also be explained. Laboratory Tests: Response to MICRONASE Tablets should be monitored by frequent urine glucose tests and periodic blood glucose tests. Measurement of glycosylated hemoglobin levels may be helpful in some patients. Drug Interactions: The hypoglycemic action of sulfonylureas may be potentiated by certain drugs including nonsteroidal antiinflammatory agents and other drugs that are highly protein bound salicylates, sulfonamides, chloramente icol probenecid coumarins, monoamine oxidase intiticin drugs tend to produce hyperglycemia and may lead to loss of control. These drugs include the thiazides and other diuretics, corticosteroids, phenothiazines, thyroid products, estrogens, oral contraceptives, phenytoin, nicotinic acid, sympathomimetics, calcium channel blocking drugs, and isoniazid. A potential interaction between oral miconazole and oral hypoglycemic agents leading to severe hypoglycemia has been reported. Carcinogenesis, Mutagenesis, and Impairment of Fertility: Studies in rats at doses up to $300 \mathrm{mg} / \mathrm{kg} / \mathrm{day}$ for 18 months showed no carcinogenic effects. Glyburide is nonmutagenic when studied in the Salmonella microsome test (Ames test) and in the DNA damage/alkaline elution assay. Pregnancy: Teratogenic Effects: Pregnancy Category B. Reproduction studies in rats and rabbits have revealed no evidence of impaired fertility or harm to the fetus due to glyburide. There are no adequate and well controlled studies in pregnant women. This drug should be used during pregnancy only if clearly needed. Insulin should be used during pregnancy to maintain blood glucose as close to normal as possible. Nonteratogenic Effects: Prolonged severe hypoglycemia ( 4 to 10 days) has been reported in neonates born to mothers who were receiving a sulfonylurea drug at the time of delivery. MICRONASE should be discontinued at least two weeks before the expected delivery date. Nursing Mothers: Some sulfonylurea drugs are known to be excreted in human milk. Insulin therapy should be considered. Pediatric Use: Safety and effectiveness in children have not been Insulin therapy
established.

ADVERSE REACTIONS: Hypoglycemia: See Precautions and Overdosage sections. Gastrointestinal Reactions: Cholestatic jaundice may occur rarely: MICRONASE Tablets should be discontinued if this occurs. Gastrointestinal disturbances, e.g. nausea, epigastric fullness, and heartburn, are the most common reactions, having occurred in $1.8 \%$ of treated patients during clinical trials. They tend to be dose-related and may disappear when dosage is reduced. Liver function abnormalities, including isolated transaminase elevations, have been reported. Dermatologic Reactions: Allergic skin reactions, e.g., pruritus, erythema, urticaria, and morbilliform or maculopapular eruptions, occurred in $1.5 \%$ of treated patients during clinical trials. These may be transient and may disappear despite continued use of MICRONASE; if skin reactions persist, the drug should be discontinued. Porphyria cutanea tarda and photosensitivity reactions have been reported with sulfonylureas. Hematologic Reactions: Leukopenia, agranulocytosis, thrombocytopenia, hemolytic anemia, aplastic anemia, and pancytopenia have been reported with sulfonylureas. Metabolic Reactions: Hepatic porphyria and disulfiram-like reactions have been reported with sulfonylureas; however, hepatic porphyria has not been reported with MICRONASE and disulfiram-like reactions have been reported very rarely. Cases of hyponatremia have been reported with glyburide and all other sulfonylureas, most often
in patients who are on other medications or have medical conditions known to cause hyponatremia or increase in patients who are on other medications or have medical conditions known to cause hyponatremia or increase
release of antidiuretic hormone. (SIADH) secretion has been reported with certain other sulfonylureas, and release of antidiuretic hormone. (SIADH) secretion has been reported with certain other sulfonylureas, and
it has been suggested that these sulfonylureas may augment the peripheral (antidiuretic) action of ADH and it has been suggested that these
/or increase release of $A D H$.

OVERDOSAGE: Overdosage of sulfonylureas, including MICRONASE Tablets, can produce hypoglycemia it hypoglycemic coma is diagnosed or suspected, the patient should be given a rapid intravenous injection of concentrated (50\%) glucose solution. This should be followed by a continuous infusion of a more dilute (10\%) glucose solution at a rate which will maintain the blood glucose at a level above $100 \mathrm{mg} / \mathrm{dL}$. Patients should be closely monitored for a minimum of 24 to 48 hours, since hypoglycemia may recur after apparent clinical recovery

Caution Federal law prohibits dispensing without prescription. Store at controlled room temperature $15^{\circ}-30^{\circ} \mathrm{C}\left(59^{\circ}-86^{\circ} \mathrm{F}\right)$. Dispensed in well closed containers with safety closures. Keep container tightly closed. For additional product information see your Upjohn representative.

\section{Upjohn}

THE UPJOHN COMPANY, Kalamazoo, MI 49001, USA 


\begin{tabular}{|c|c|c|c|c|c|c|}
\hline \multirow[b]{2}{*}{ Activity } & \multicolumn{2}{|c|}{$\begin{array}{c}\text { Externs } \\
(\mathrm{n}=7)\end{array}$} & \multicolumn{2}{|c|}{$\begin{array}{r}\text { Interns } \\
(\mathrm{n}=7)\end{array}$} & \multicolumn{2}{|c|}{$\begin{array}{l}\text { Resident } \\
(\mathrm{n}=1)\end{array}$} \\
\hline & $\begin{array}{l}\text { Total } \\
\text { hours }\end{array}$ & $\begin{array}{c}\% \\
\text { of } \\
\text { total }\end{array}$ & $\begin{array}{l}\text { Total } \\
\text { hours }\end{array}$ & $\begin{array}{c}\% \\
\text { of } \\
\text { total } \\
\end{array}$ & $\begin{array}{l}\text { Total } \\
\text { hours }\end{array}$ & $\begin{array}{c}\% \\
\text { of } \\
\text { total } \\
\end{array}$ \\
\hline Rounds & 26.4 & 26.1 & 19.9 & 17.6 & 36.8 & 46.8 \\
\hline Patient evaluation & 4.2 & 4.1 & 29.1 & 25.7 & & \\
\hline Personal & 22.2 & 22.0 & 15.3 & 13.5 & 14.9 & 18.9 \\
\hline $\begin{array}{l}\text { Performing history taking } \\
\text { and physical examination }\end{array}$ & 19.8 & 19.6 & 13.3 & 11.7 & 0.5 & 0.6 \\
\hline Reading & 13.7 & 13.6 & 9.1 & 8.0 & 7.0 & 8.9 \\
\hline Procedure observation & 3.5 & 3.5 & 7.0 & 6.2 & & \\
\hline $\begin{array}{l}\text { Observing or performing } \\
\text { consultation }\end{array}$ & 4.2 & 4.1 & 5.8 & 5.1 & 2.8 & 3.6 \\
\hline On call & & & 7.8 & 6.9 & & \\
\hline $\begin{array}{l}\text { Case discussion } \\
\text { Attending lecture }\end{array}$ & 2.0 & 2.0 & 1.6 & 1.4 & $\begin{array}{l}7.6 \\
0.5\end{array}$ & $\begin{array}{l}9.6 \\
0.6\end{array}$ \\
\hline $\begin{array}{l}\text { Attending lecture } \\
\text { Reading x-rays }\end{array}$ & $\begin{array}{l}2.7 \\
0.8\end{array}$ & $\begin{array}{l}2.6 \\
0.8\end{array}$ & $\begin{array}{l}1.8 \\
1.7\end{array}$ & $\begin{array}{l}1.6 \\
1.5\end{array}$ & & \\
\hline $\begin{array}{l}\text { Drawing arterial blood } \\
\text { gas samples }\end{array}$ & 0.5 & 0.5 & 0.6 & 0.5 & & \\
\hline $\begin{array}{l}\text { Miscellaneous procedures } \\
\text { Inserting central venous }\end{array}$ & & & & & 3.9 & 5.0 \\
\hline $\begin{array}{l}\text { Inserting central venous } \\
\text { pressure catheter }\end{array}$ & 0.4 & 0.4 & & & 3.5 & 4.4 \\
\hline Drawing venous blood & 0.1 & 0.1 & 0.1 & 0.1 & & \\
\hline Reading ECGs & 0.2 & 0.2 & 0.2 & 0.2 & 1.3 & 1.6 \\
\hline Observing bronchoscopy & 0.4 & 0.4 & & & & \\
\hline Total & $\overline{101.1}$ & $\overline{100.0}$ & $\overline{113.3}$ & $\overline{100.0}$ & 78.8 & $\overline{100.0}$ \\
\hline
\end{tabular}

time reported; therefore, the work burden may not be as large as one would expect. In a time study of house officers on a medical service, LaPalio ${ }^{1}$ found that subjects spent from 91 to 105 hours on duty in a seven-day period, which is similar to the time reported in the present study.

In analyzing this data, the ways in which time is used by the various groups must be considered. Table 4 reveals that rounds occupied a significant amount of time for externs and the single resident. The question that has been raised many times and that as yet has not been answered successfully is, 'Educationally, how beneficial are rounds?' It would appear that rounds conducted by an astute, educationally oriented physician should maximize learning outcome. However, to date there are no systematic research findings to substantiate this hypothesis. All too often, house staff members complain that rounds are of little benefit to their overall learning program. If this pronouncement contains even partial truth, a significant amount of time is being used for a nonoptimal learning activity.

Interns devoted the majority of their time in patient evaluation activities not included within the parameters of our study. The intern study participants felt that in many instances these patient evaluations could have been handled by nurses or paramedical personnel, which would allow more time to participate in more beneficial activities.

The percentages of time spent on history taking and physical examinations by externs, interns, and the resident were $19.6 \%, 11.7 \%$, and $0.6 \%$, respectively. The relative distribution of time for training level was as expected. The amount of time devoted to reading and in case discussion was disturbingly low for all levels. Time redistribution might be considered in an attempt to leave more time for reading.

Consultation activities also rated low in the amount of time spent. In most instances, trainees would benefit from observing a skilled clinician in the performance of consultation. Case discussion following these observations also would be of benefit, and, therefore, it would be advisable for house staff officers to spend more time in this way.

Adequate exposure to various types of cases is important in the training of house staff members. This study concentrated on an internal medicine service in which 212 different diagnoses were reported in a seven-day period. The frequency distribution of these diagnoses does not seem particularly unusual, except that $6.1 \%$ of the total frequencies reported were chronic renal failure. This is explained by the fact that two of the study participants were on nephrology service during the study period. Otherwise, it appears that the trainees had exposure to a wide variety of cases. 


\begin{tabular}{|lcc|}
\hline \multicolumn{3}{|l|}{ TABLE 5. TWENTY-FIVE MOST FREQUENTLY REPORTED DIAG- } \\
NOSES. & Frequency & $\begin{array}{c}\text { Percent } \\
\text { of total }\end{array}$ \\
\hline Diagnosis & 130 & 14.6 \\
\hline Diabetes mellitus & & \\
Chronic obstructive & 94 & 10.5 \\
lung disease & 94 & 10.5 \\
Chronic renal failure & 69 & 7.7 \\
Acute myocardial infarction & 61 & 6.8 \\
Cerebral vascular accident & 39 & 4.4 \\
Multiple myeloma & 34 & 3.8 \\
Acute gastroenteritis & 33 & 3.7 \\
Congestive heart failure & 33 & 3.7 \\
Asthma & 31 & 3.5 \\
Lung tumor & 26 & 2.9 \\
Diabetic ketoacidosis & 24 & 2.7 \\
Anemia & 23 & 2.6 \\
Respiratory failure & 22 & 2.5 \\
Angina pectoris & 21 & 2.4 \\
Crohn's disease & 19 & 2.1 \\
Colonic polyps & 19 & 2.1 \\
Chest pain & 18 & 2.0 \\
Carcinoma of colon & 18 & 2.0 \\
Hematuria & 16 & 1.8 \\
Acute phlebitis & 16 & 1.8 \\
Lymphoma & 16 & 1.8 \\
Urinary tract infection & 16 & 1.8 \\
Seizure disorder & 15 & 1.7 \\
Cardiac arrest & 4 & 0.4 \\
Esophageal stricture & 891 & 100.0 \\
\hline Total & & \\
\hline
\end{tabular}

\begin{tabular}{|c|c|c|}
\hline \multirow{2}{*}{$\begin{array}{l}\text { Training } \\
\text { level }\end{array}$} & \multicolumn{2}{|c|}{ Percent of activities } \\
\hline & Performed & Observed \\
\hline $\begin{array}{l}\text { Extern } \\
\text { Intern } \\
\text { Resident }\end{array}$ & $\begin{array}{l}42.2 \\
80.0 \\
52.7\end{array}$ & $\begin{array}{l}57.8 \\
20.0 \\
47.3\end{array}$ \\
\hline
\end{tabular}

It is safe to assume that a significant amount of learning in medical education comes from independent study and observation, yet trainees could benefit from the experience and knowledge of others. Externs reported having others present only $38.1 \%$ of the time during the performance of an activity or procedure. Interestingly, interns reported others present $56.2 \%$ of the time. This might indicate that interns have learned to take advantage of the knowledge and experience of others. One would expect that residents would be the most independent of those studied; yet, residents should be willing to teach lower level trainees. This was not evident in this study, in that the resident reported others present only $5.7 \%$ of the time.

The data concerning observation versus performance of activities and procedures are not particularly surprising in that house staff members gen- erally are allowed to perform procedures when they are capable of doing so. This is an educationally beneficial endeavor and should be continued so long as experienced clinicians are satisfied that the trainees are competent in the performance of the procedure.

Although the literature contains several time studies of various types and classes of medical practitioners, there are only a few that analyze the ways in which trainees spend their time. Girard and associates have conducted several studies designed to profile professional activities and patient care services of medical and surgical specialists, and one $e^{2}$ of these profiled the specialty of internal medicine. The mean number of professional work hours per week for an internist practicing general internal medicine was 53.3. The mean number of patient care hours per day was 5.8 , with the rest of the time being spent in teaching, research, administration, travel, and on call. These data differ from those in our study; however, one must note the differences between the practicing physician and the trainees in the way time was spent. It seems evident that the efficiency of the practicing physician is of importance when considering the data.

Girard and associates ${ }^{2}$ also looked at the distribution of diagnoses seen by the internists. Their classification was of a more universal nature than was the one in our study. They reported that $28.4 \%$ of the diagnoses involved diseases of the circulatory system, $13.5 \%$ diseases of the respiratory system, $7.8 \%$ neoplasms, $7.2 \%$ endocrine, nutritional, and metabolic diseases, and $6.6 \%$ diseases of the digestive system. If one considers our 25 most frequently reported diagnoses and attempts to fit them into general categories, it appears that the distribution would be similar between the two studies.

A recent report from the Association of American Medical Colleges ${ }^{3}$ contains several recommendations that can be viewed in light of the present study. An important one is that students with the ability to learn independently should be provided opportunities to further develop this skill, while students without this attribute should be challenged to develop it. At face value, the present study indicates that little time is spent in independent study ( $10.3 \%$ of time across all groups), a fact that should be of concern to medical educators.

Another recommendation was that the level of knowlege and skills needed before graduate medical education is begun should be defined more clearly. If this can be accomplished, the trainees hopefully will become more efficient in their use of time. Medical schools and medical training fa- 


\begin{tabular}{|c|c|c|c|}
\hline Diagnosis & Students & $\begin{array}{l}\text { Interns and } \\
\text { residents }\end{array}$ & Total cases \\
\hline Diabetes mellitus & 86 & 44 & 130 \\
\hline $\begin{array}{l}\text { Chronic obstructive } \\
\text { lung disease }\end{array}$ & 47 & 47 & 94 \\
\hline Chronic renal failure & 42 & 52 & $\begin{array}{l}94 \\
94\end{array}$ \\
\hline Acute myocardial infarction & 23 & 46 & 69 \\
\hline Cerebral vascular accident & 13 & 48 & 61 \\
\hline Multiple myeloma & 26 & 13 & 39 \\
\hline Acute gastroenteritis & 2 & 32 & 34 \\
\hline Congestive heart failure & 6 & 27 & 33 \\
\hline Asthma & 20 & 13 & 33 \\
\hline Lung tumor & 22 & 9 & 31 \\
\hline Diabetic ketoacidosis & 5 & 21 & 26 \\
\hline Anemia & 17 & 7 & 24 \\
\hline Respiratory failure & 11 & 12 & 23 \\
\hline Angina pectoris & 15 & 7 & 22 \\
\hline Crohn's disease & 10 & 11 & 21 \\
\hline Colonic polyps & 3 & 16 & 19 \\
\hline Chest pain & 2 & 17 & 19 \\
\hline Carcinoma of colon & 5 & 13 & 18 \\
\hline Hematuria & 12 & 6 & 18 \\
\hline Acute phlebitis & 13 & 3 & 16 \\
\hline Lymphoma & 8 & 8 & 16 \\
\hline Urinary tract infection & 8 & 8 & 16 \\
\hline Seizure disorder & 7 & 9 & 16 \\
\hline Cardiac arrest & 1 & 14 & 15 \\
\hline Esophageal stricture & 1 & $\frac{3}{3-1}$ & 4 \\
\hline Total & 405 & 486 & 891 \\
\hline
\end{tabular}

cilities also must evaluate the learning style of trainees and tailor training methods to learning style. If this is accomplished, the time distribution in postgraduate training may be altered dramatically.

If trainees are encouraged to learn independently, they will need to spend more of their time in that activity and less in some of the others outlined in this study. One might consider a reduction in the time spent in 'ineffective' rounding and in such areas as procedure observation and personal time.

The report ${ }^{3}$ went on to emphasize that knowledge, skills, and values must be outlined for the period of clinical education, a recommendation that all educators involved in postgraduate education should consider carefully. Intertwined throughout the report are various references to evaluation procedures. If we are better able to evaluate performance, we might well be more prepared to recommend more efficient use of time by trainees.

\section{Summary}

This study analyzed the amount of time spent by various levels of trainees while on duty during a seven-day period. A significant number of hours were spent on duty by the trainees during the time of the study. Relationships were demonstrated between the types of activities and procedures reported and the level of training as well as between the level of training and whether an activity was observed or performed. Various educational implications of the findings were outlined.

1. LaPalio LR: Time study of students and house staff on a university medical service. $J$ Med Educ 1981; 56(January):61-64.

2. Girard RA, Mendenhall RC, Tarlov AR, et al: A national study of internal medicine and its specialties: 1 . An overview of the practice of internal medicine. Ann Intern Med 1979;90:965-975.

3. Association of American Medical Colleges: Physicians for the twentyfirst century. $J$ Med Educ 1984;59(November):1-42.

From the Division of Educational Resources, College of Medicine, Wayne State University, Detroit. Dr Wood is now the associate dean, Michigan State University-College of Osteopathic Medicine, East Lansing, Mich.

Reprint request to Dr Wood, MSU-COM, A309 Fee Hall, East Lansing, MI 48824. 


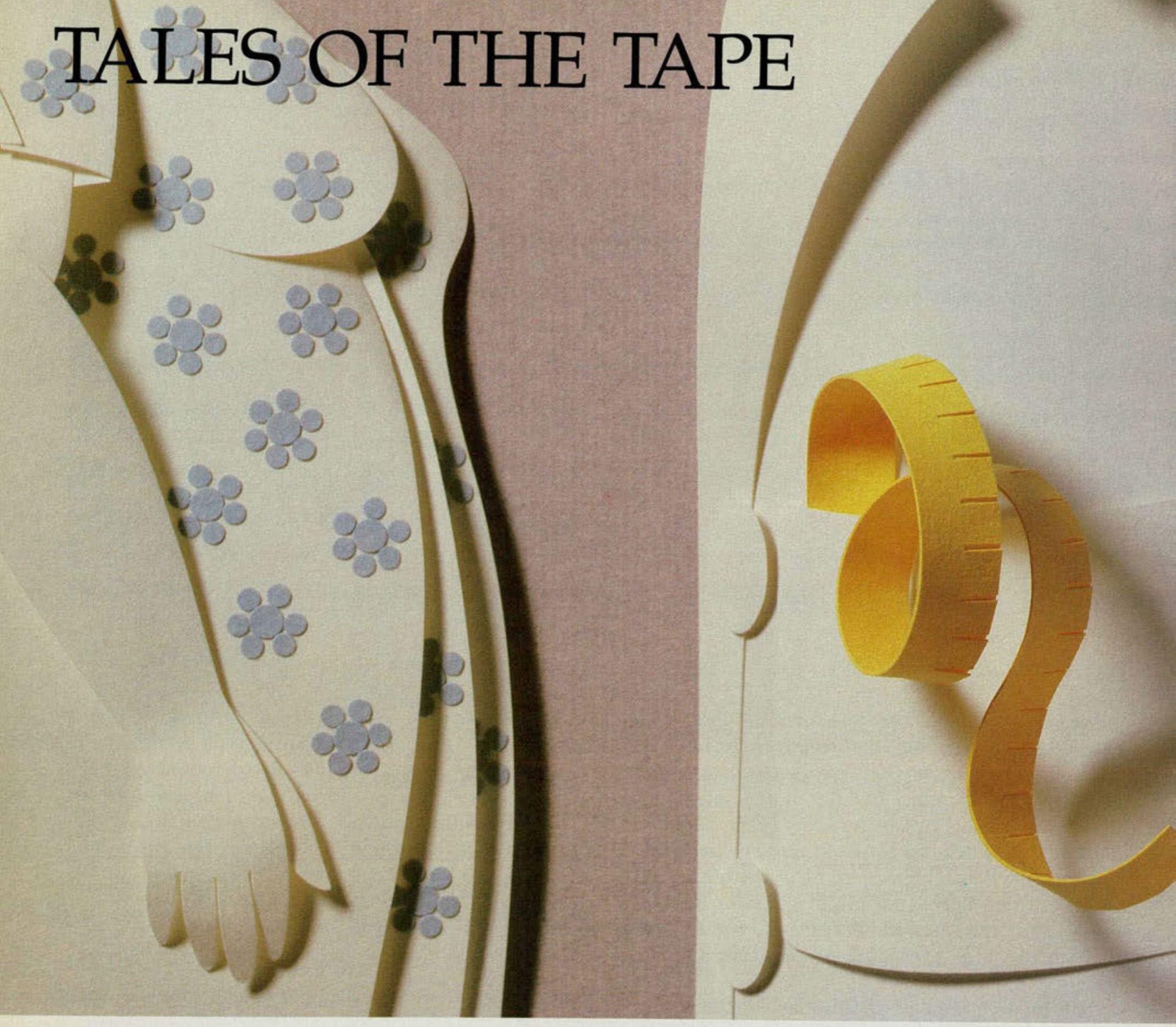

\section{"...but I only eat once a day."}

You've heard it many times before, but the response is never simple. Successful weight control is the result of a complex interplay of diet, exercise and behavior modification... strengthened by the motivation early weight loss can bring.

ADIPEX-P® can help provide the early motivation your patient needs to succeed in a comprehensive, physician-supervised weight loss program.

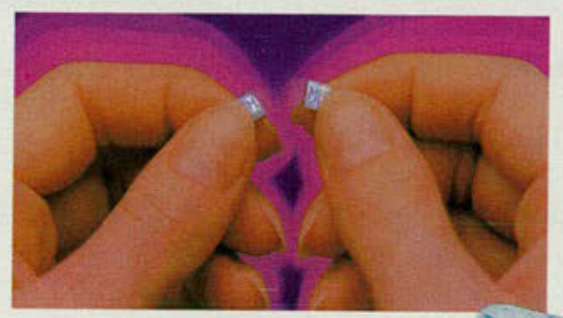

For safe appetite suppression when it's needed most. .

Prescribe ADIPEX-P' $\mathbb{1}$ (phentermine $\mathrm{HCl} 37.5 \mathrm{mg}$ )

Please see adjacent page for summary of prescribing information.

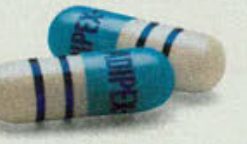

LEMMON

(c) 1988 LEMMON Company

Sellersville, PA 18960 